\title{
Commentary: The impact of climate change on landslides in southeastern of high-latitude permafrost regions of China
}

\author{
Drandreb Earl O. Juanico* \\ Research and Development Management Office, Technological Institute of the Philippines, Manila, Philippines
}

Keywords: urban heat island, diurnal temperature range, permafrost thaw, landslides, China

\section{A commentary on}

The impact of climate change on landslides in southeastern of high-latitude permafrost regions of China

by Shan, W., Hu, Z., Guo, Y., Zhang, C., Wang, C., Jiang, H., et al. (2015). Front. Earth Sci. 3:7. doi: 10.3389/feart.2015.00007

OPEN ACCESS

Edited by:

Davide Tiranti,

Regional Agency for Environmental

Protection of Piemonte, Italy

Reviewed by:

Fabio Matano,

National Research Council, Italy

*Correspondence:

Drandreb Earl O. Juanico djuanico@gmail.com

Specialty section:

This article was submitted to Quaternary Science, Geomorphology and Paleoenvironment, a section of the journal Frontiers in Earth Science

Received: 22 December 2015

Accepted: 19 January 2016

Published: 05 February 2016

Citation:

Juanico DEO (2016) Commentary:

The impact of climate change on

landslides in southeastern of

high-latitude permafrost regions of

China. Front. Earth Sci. 4:11.

doi: 10.3389/feart.2016.00011
Permafrost melting could trigger geomorphic change processes on the Earth's surface, such as landslides, ground subsidence, and erosion. Although permafrost accounts for a minute portion of the Earth's total water content, it occurs at substantial concentrations in high latitudes of the Northern Hemisphere. Permafrost also locks in high amounts of greenhouse gases, such as carbon dioxide and methane. Consequently, the accelerated thawing, associated with the rise in global temperatures, could release more greenhouse gasses to the atmosphere, thus, contributing to further atmospheric warming. In northeastern China, near the Siberian border, some documented landslides raised concerns about the safety of a segment along the National Highway 202. The study by Shan et al. (2015) hypothesized that permafrost melting drives the occasional landslides in the area.

Shan et al. (2015) fell short of demonstrating the impact of climate-driven permafrost melting as the landslide trigger in their study area. The authors attempted to link permafrost thawing to the significant rapid increase in average minimum air temperatures compared to the average maximum temperatures. These asymmetric rates lead to a declining diurnal temperature range (DTR), considered as an important indicator of climate change (Qu et al., 2014). The authors recognized the presence of human construction activities in the area but made no attempt to rule these out as landslide triggers. The study also seems perplexed in attributing whether permafrost thawing is the cause or effect of the signature DTR trends. Despite presenting pieces of evidence, the authors did not convincingly show that permafrost thawing, due to climate change, significantly induced landslides.

Declining DTR appears widespread, even in latitudes too low for permafrost to exist. Between 1911 and 2012, the annual mean DTR has been falling across all regions in the continental United States. For example, at low-latitude Tucson, AZ, Comrie (2000) found evidence for a declining DTR between 1949 and 2005. The Daqing River Basin, south of Beijing, where permafrost obviously does not exist, also exhibit DTR downtrends between 1961 and 2010. Concerning seasonal averages, winter DTRs appear to decline the most (Liu et al., 2014). In contrast, Shan et al. $(2015$, p. 9) attribute the observed DTR downtrend in Sunwu County particularly to 
"the latent heat of permafrost thaw." Regardless of the presence of permafrost, the DTR downtrends appear to be global, nevertheless.

With much focus latched on global climate change impacts, researchers often sidestep the intensification of human activity as a driver for local warming uptrends. Shan et al.'s (2015, p. 9) observation of an interannual decrease in pore water pressure rules out precipitation as a major landslide trigger. Instead of permafrost thawing, however, the warming trends could be explained by one and oft-ignored alternative hypothesisthe "Urban Heat Island" (UHI) effect. The UHI effect points to rapid urbanization as the underlying culprit for the declining DTRs in many towns, regardless of latitude. The faster increase of minimum compared to maximum temperatures is due to land use changes brought by urban development to accommodate growing human populations (Guido, 2008).

The UHI effect is evident in the same dataset from which Shan et al. (2015) based their analysis (Figure 1). Gathering daily temperature data for Sunwu County, from TuTiempo S.L., the yearly mean DTR was calculated for select years that match with China's census sampling. The National Bureau of Statistics of China publishes values of the urbanization rate for the following census years: 1953, 1964, 1982, 1990, 2000, and 2010. The mean DTR has indeed been declining at Sunwu County (Figure 1A), while the urbanization rate all over China has been increasing over, roughly, the same period (Figure 1B). Both trends are inversely related (Figure 1C). Indeed, evidence for a significantly very strong, negative correlation (Spearman $\rho=-0.90, p=0.0159$ at $\alpha=0.05$ ) between urbanization and DTR trends is found. Consequently, there is likely a strong association between the rapid urbanization in the towns connected by the Bei'an-Heihe highway and the local warming trends.

The observed DTR decline might simply be a signature of increasing human presence due to urbanization. Human activity can, indeed, cause landslides. Vehicular vibration along the highway, in addition to on-going construction works, might contribute enough power to trigger landslides in a previously undisturbed area (Moreiras, 2004). Persistent precipitation, even at non-trending rates, in combination with vibrational loads, could drive landslide activity, with or without permafrost thawing, as a tabletop experiment showed (Juanico et al., 2008). Landslide hazards along highways is a major problem even in areas with no evident permafrost thawing (Gurugnanam et al., 2013). Of course, permafrost melt could contribute toward loosening the soil. However, concluding that it is "the main cause of landslide movement" fails to appreciate the significant role of urbanization in changing the Earth's landscape.

Rapid urbanization and geomorphic changes may together have a complex association that deserves a closer look. The energetic processes of growing human settlements could directly or indirectly induce geomorphic evolution at local scales. The emission of greenhouse gasses from industrial production leads to climate warming that might increase the rate of

\section{A Annual Average DTR, Sunwu County}

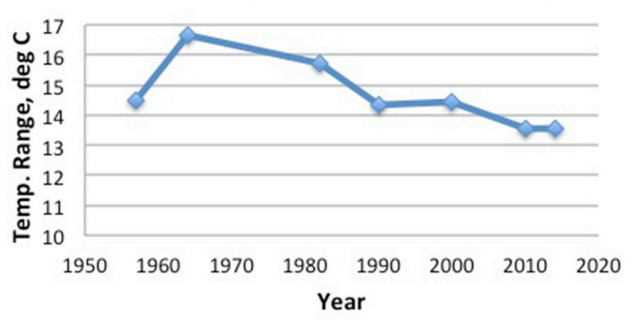

B

Urbanization Rate, China

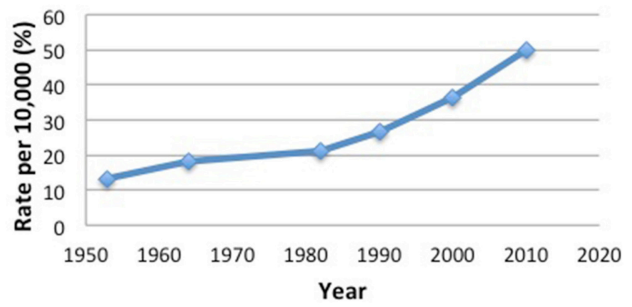

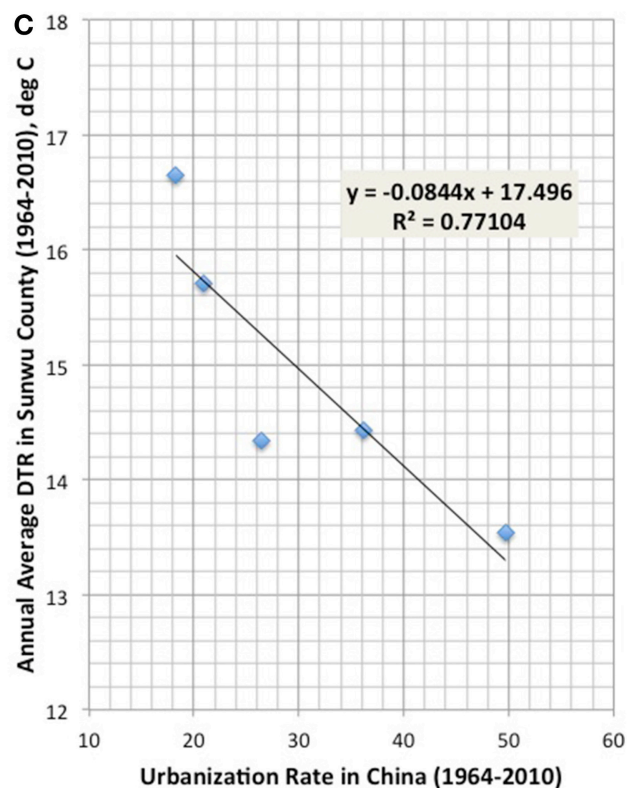

FIGURE 1 | Relationship between DTR and urbanization. (A) Annual average diurnal temperature ranges in Sunwu County for the years 1957, 1964, 1982, 1990, 2000, 2010, and 2014, from TuTiempo S.L. (http://en.tutiempo.net/climate/05-1964/ws-505640.html); (B) Urbanization rate in China from the China Statistical Yearbook 2013 for the years 1953, 1964, 1982, 1990, 2000, and 2010 (http://www.stats.gov.cn/tjsj/ndsj/2013/indexeh.htm); (C) Scatterplot showing the inverse relationship between annual average DTR and urbanization rate on corresponding years, with square of the Pearson R equal to 0.77 , as indicated below the trendline equation. 
geomorphic processes, such as landslides. Shan et al. (2015) attempted to demonstrate this indirect link, regarding permafrost thaw, as the primary cause of landslides. On the other hand, the direct link is precisely the existence of the highway, possibly a difficult confounding factor to isolate or rule out. Indeed, the authors indicate that "human. . . activity accelerates the thawing of permafrost" (Shan et al., 2015, p. 10). The extent of the contribution of vibrational loads generated by highway traffic to the landslide activity might require further attention.

\section{REFERENCES}

Comrie, A. C. (2000). Mapping a wind-modified urban heat island in Tucson, Arizona. Weather Bull. Am. Meteorol. Soc. 81, 2417-2431. doi: 10.1175/1520-0477(2000)081<2417:MAWMUH > 2 . 3. $\mathrm{CO} ; 2$

Guido, Z. (2008). Urban Heat Island: Raising City Temperatures. Available online at: http://www.southwestclimatechange.org/impacts/people/urban-heat-island (Accessed December 22, 2015).

Gurugnanam, B., Arunkumar, M., Venkatraman, A. T., and Bairivi, S. (2013). Assessment on landslide occurrence: a recent survey in Nilgiri, Tamil Nadu, India. Int. J. Sci. Environ. Technol. 2, $1252-1256$.

Juanico, D. E., Longjas, A., Batac, R., and Monterola, C. (2008). Avalanche statistics of driven granular slides in a miniature mound. Geophys. Res. Lett. 35:L035567. doi: 10.1029/2008GL035567

Liu, W., Li., C., Liu, J., Yan, D., and He, L. (2014). “Trends in temperature extremes during 1961-2010 in Daqing River Basin," in Modeling and Computation in Engineering III, eds L. Zhang and L. Xie (Boca Raton, FL: CRC Press), $273-278$.
AUTHOR CONTRIBUTIONS

The author confirms being the sole contributor of this work and approved it for publication.

\section{ACKNOWLEDGMENTS}

The author expresses gratitude to Gwenaël Courvoisier from the Frontiers in Earth Science Editorial Office, and funding support from the DOST-GIA Grant 2014-7373.

Moreiras, S. M. (2004). Landslide incidence zonation in the Rio Mendoza valley, Mendoza province, Argentina. Earth Surf. Process. Land. 29, 255-266. doi: 10.1002/esp.1056

Qu, M., Wan, J., and Hao, X. (2014). Analysis of diurnal air temperature range change in the continental United States. Weather Clim. Extremes 4, 86-95. doi: 10.1016/j.wace.2014.05.002

Shan, W., Hu, Z., Guo, Y., Zhang, C., Wang, C., Jiang, H., et al. (2015). The impact of climate change on landslides in southeastern of high-latitude permafrost regions of China. Front. Earth Sci. 3:7. doi: 10.3389/feart.2015.00007

Conflict of Interest Statement: The author declares that the research was conducted in the absence of any commercial or financial relationships that could be construed as a potential conflict of interest.

Copyright (c) 2016 Juanico. This is an open-access article distributed under the terms of the Creative Commons Attribution License (CC BY). The use, distribution or reproduction in other forums is permitted, provided the original author (s) or licensor are credited and that the original publication in this journal is cited, in accordance with accepted academic practice. No use, distribution or reproduction is permitted which does not comply with these terms. 